\title{
SEXUALIDAD Y ORDEN SOCIAL: LA VISION MEDICA EN LA ESPAÑA DEL PRIMER TERCIO DEL SIGLO XIX
}

\section{José Martínez}

\section{Introducción}

Es un hecho incuestionable que la Medicina se encuentra estrechamente relacionada con la Política. La tarea de gobernar exige numerosas veces, para ser eficaz, recurrir a la ciencia médica. Contemplando nuestro pasado esta conexión presenta dos momentos especialmente significativos. El primero de ellos sería el correspondiente al período de surgimiento del Estado moderno. Como ha puesto de relieve Maravall, la exigencia de un gran Estado, como era el español del siglo XVI, de poseer una considerable masa de población para cubrir sus necesidades de soldados y trabajadores manuales, llevó a los gobernantes a interesarse por la salud individual y colectiva de sus súbditos y a hacer de una y otra objetivos de la política gubernamental (1). Ello trajo como consecuencia inmediata la participación de los médicos en las tareas de gobierno, participación que se puso sobre todo de manifiesto en las múltiples consultas que las autoridades estatales y municipales hicieron a los médicos con motivo de las epidemias padecidas por nuestro país desde finales del siglo XVI hasta el último cuarto de la siguiente centuria.

Otro momento de especial relieve en las relaciones entre Medicina y Política dentro de nuestras fronteras se produjo a finales del siglo XVIII. El afán de nuestros monarcas ilustrados por cumplir con la exigencia de suministrar felicidad a sus súbditos y por mantener una población numerosa les condujo a plantearse como uno de los fines princi- 
pales de su programa político el cuidado de la salud de los ciudadanos (2). Fruto de ello fueron el gran número de disposiciones legales encaminadas a promover la higiene pública que se dictaron en esos años (3), lo que, a su vez, trajo consigo un más alto protagonismo de los profesionales de la Medicina en las tareas legislativas. Como era de esperar, los médicos tomaron rápidamente conciencia del creciente papel que estaban jugando a la hora de establecer las normas destinadas a regular las relaciones entre los miembros de la sociedad. Clara expresión de ello fue la aparición dentro de nuestras fronteras de dos obras -Pensamientos sobre la razón de las leyes (1810) de Ramón López Mateos (1771-1814) y Filosofía de la legislación natural (1830) de Francisco Fabra Soldevilla (1778-1839) - cuyos autores, médicos de profesión, defendían la tesis de que los saberes que la Medicina suministraba acerca del hombre debían ser la fuente fundamental de conocimiento en que debía basarse todo código legislativo. Ambos proporcionaban además en sus obras un catálogo completo de los principios que, inspirados en ese conocimiento del hombre obtenido a partir de la Medicina, debía tener en cuenta un jurista de manera ineludible si es que quería legislar de manera adecuada. Naturalmente, dentro de ellos figuraban los que tenían que ver con el lugar y la función del hombre dentro de la sociedad y con la vida sexual de uno y otro. Intentar mostrar los puntos de vista de López Mateos y Fabra sobre estas cuestiones es el objetivo fundamental de este trabajo. Ello servirá no sólo para conocer cuáles eran las recomendaciones al respecto que estos médicos daban para conseguir un buen ordenamiento de la sociedad, sino también para comprender mejor el papel jugado por los médicos españoles en el establecimiento de un determinado modelo de actitud social frente al sexo y la vida sexual.

Para llevar a cabo adecuadamente esta tarea es preciso aludir previamente a aquello que en mi opinión hizo posible la aparición de unas obras de las características de las de López Mateos y Fabra. Me refiero al cambio que tuvo lugar a finales del siglo XVIII y comienzos del XIX en el modo de entender por parte de los médicos las relación entre Medicina y Derecho.

Una nueva actitud de los médicos con respecto al Derecho

El cambio de actitud que los médicos mostraron con respecto al Derecho en los años finales del Setecientos y primeros del Ochocientos, 
su afán por transformarse en legisladores sin dejar de ser los expertos testigos que hasta entonces habían sido, se aprecia de manera clara con sólo contemplar el nuevo modo de concebir la Medicina Legal que va a surgir en esos años. Esta modificación en el modo de entender esta disciplina es mostrada claramente por Paul-Agustín-Oliver Mahon (1752-1801) en las páginas de su Médecine légale, et Police médical. Allí manifestaba que:

«La Medicina Legal, Medicina forensis, jurídica, es el arte de aplicar los conocimientos y los preceptos de la Medicina a las diferentes cuestiones del derecho, para aclararlas o interpretarlas convenientemente.

El arte de hacer los informes o relaciones a la justicia, no es más que una parte de la Medicina Legal; y se les puede reprochar a quienes afirmaron lo contrario, de haber sustituido una ciencia extensa y trascendente por su naturaleza y su objeto, por el ejercicio técnico de una sola de sus partes» (4).

Los nuevos tratadistas de Medicina Legal confieren a la disciplina un mayor campo de acción. No la limitan a ser, como hicieron Ambroise Paré (1510-1590), Giovanni Filippo Ingrassia (1510-1580), Juan Fragoso (ca. 1530-1597) y Giovanni Baptista Codronchi (1547-1628), un mero conjunto de saberes destinados a ilustrar a los médicos y cirujanos sobre el modo de llevar a cabo sus peritajes forenses (5). Ya no era esa simple agrupación de «materias médicas que pertenecen a los nıedios de ser conocido lo que es conforme con la ley", con que el muy influyente Paolo Zacchia (1584-1659) se refería al contenido de sus Questiones medico-legales (6), sino que se han transformado además en aquella parte de la Medicina destinada a elaborar y perfeccionar los propios códigos legislativos. En efecto, para un número importante de autores, entre quienes se econtraron los más influyentes, la Medicina Legal no será tan sólo un conjunto de cuestiones destinadas a ayudar a los jueces en la resolución de los diferentes casos que pueden plantearse ante un tribunal, sino que será aquella parte de la Medicina que tiene que ver con la prevención, diagnóstico y tratamiento de las enfermedades no ya del cuerpo humano, sino del cuerpo político, del Estado.'

Este nuevo modo de entender la relación entre Medicina y Derecho encontró en la Francia postrevolucionaria a sus más ardientes defensores y un ambiente más propicio para desarrollarse (7). Las nuevas instancias en el poder necesitaban contar con un nuevo marco jurídico que superara al del Antiguo Régimen y la Medicina, como portadora 
de unos saberes calificados como científicos, podía resultar muy útil para acreditar y consolidar el nuevo orden social que se trataba de imponer (8). No debe extrañar, por tanto, que se mostraran receptivas con respecto a las novedades que en relación con el papel que había de jugar la Medicina en el Derecho portaba el nuevo modo de entender la correspondencia entre ambas. Prueba de ese interés es la aparición en poco tiempo de dos obras dedicadas a la Medicina Legal, además de la ya mencionada de Mahón, y que como ésta son también defensoras de su mismo modo de entender la disciplina. Así, en su afamado Les lois éclairées par les sciences physiques, ou Traité de médecine légale et d'hygiène publique (1797), François Emmanuel Foderé (1764-1835) confiere a la Medicina Legal el carácter de disciplina médica destinada a servir en las tareas de gobierno del Estado, expresándolo en los siguientes términos en la introducción de su obra:

«La Medicina legal puede considerarse baxo dos aspectos igualmente interesantes á la salud pública. Baxo el primero y mas general, diremos que es el estudio de todas las leyes conocidas de la física animal, y la ciencia de su aplicación á todas las instituciones que se han originado del órden social. En este caso no solo abraza la naturaleza del hombre, sino también todos los objetos con los cuales está unida y enlazada; y como las leyes no pueden ser buenas si no estan de acuerdo con el hombre, con su corazón, necesidades, clima, y género de vida á que estan sujetos los diferentes pueblos, deben los legisladores y los magistrados consultar la medicina, vasto código de las leyes de la física animal, ántes de pensar en establecer nuevas instituciones, ó para darlas todo el grado de utilidad que son capaces de recibir. He aquí el primer sentido en que debe entenderse esta unión de palabras, medicina y leyes, Medicina legal»(9).

Las palabras de Foderé son bien explícitas. Con un sentido amplio concibe a la Medicina Legal como aquella parte de la Medicina que suministra los saberes destinados a ser empleados en las tareas de elaboración de las normas que regulan las relaciones de los hombres dentro del Estado.

Esa misma es la manera en que Jean Jacques Belloc (1730-1807) entendía la disciplina. Así lo muestra el siguiente párrafo extraído de su Cours de médecine légale, judiciaire théorique et pratique (1800):

«El Médico tiene por fin principal la curación de las enfermedades que atacan al hombre; pero el objeto de sus conocimientos no de- 
be limitarse á esto únicamente, y aunque deba servir con sus talentos á cada individuo en particular, debe con más razón dedicarlos á los intereses generales de la sociedad. Considerando la Medicina bajo estos dos aspectos, se la puede dividir en clínica ó práctica, y en política o legal» (10).

Y para aclarar aún más su división de la Medicina añadía de inmediato lo siguiente:

«La primera [La Medicina clinica] se ejercita en la curación de las enfermedades, sea en vista de la exploración de los síntomas, hecha a la cabecera de los enfermos, sea en la decisión de las consultas. La segunda [la Medicina política] tiene por objeto todo cuanto puede interesar a la salud de los hombres reunidos en sociedad, y se subdivide en tres partes, a saber, la Medicina legal propiamente dicha, que da al legislador las luces necesarias para la formación de las leyes, que dicen relación con los conocimientos médicos; la Medicina administrativa, que otros llaman policía médica, y que comprende el tratamiento de las epidemias, los medios de atajar los contagiosos, de destruir las enfermedades endémicas, de purificar una habitación, una ciudad, un territorio, etc., y la Medicina judicial o forense, que ilustra a los tribunales y otras autoridades para decidir las causas civiles y criminales que deben conocer» (11).

Las anteriores palabras de Belloc, que muestran cómo los contenidos de la Medicina Legal no se hallaban aún completamente separados de la Higiene Pública (12), expresan claramente el nuevo papel que el médico se siente llamado a jugar con respecto al Derecho. Ya no se trata de participar como mero testigo para ayudar a los jueces a resolver un caso, sino, como vengo señalando, de entrar a formar parte en las tareas de elaboración de las leyes (13). Los médicos reclaman para sí un lugar en la Administración del Estado, un puesto en algo tan importante' como es la redacción de las leyes por las que debe regularse la relación entre los ciudadanos. Solicitan un papel dentro de los mecanismos dedicados a elaborar las normas destinadas a mantener el orden dentro de la sociedad.

No se mantuvo ajena España a estas ideas. La publicación en castellano, en 1796, con el título de Medicina y Cirugía forense o legal de los Elementa medicine et chirurgia forensis que el cirujano vienés Joseph Jakob Plenk (1733-1807) había publicado por primera vez en Viena en 1781, así como la rápida versión en nuestra lengua de la obra de Foderé, 
aparecida en Madrid entre 1901 y 1903, pusieron tempranamente en contacto a los médicos españoles con el nuevo modo de entender su papel con respecto a la administración del Estado que estaba cobrando fuerza en las zonas más influyentes de la Medicina europea de la época. En concreto, la obra de Plenk sirvió de guía fundamental para la docencia de la Medicina Legal en un centro de tanta significación dentro del desarrollo de la Medicina española como fue el Colegio de Cirugía de San Carlos (14). Los médicos y cirujanos españoles dispusieron así de una obra en la que se afirmaba que la Medicina forense era una "ciencia» cuyo objeto "son todas las acciones del cuerpo humano, o cosas que dañan la vida, o la salud, o la felicidad pública» (15), una obra que, por tanto, presentaba a la disciplina como una parte de la Medicina cuyo fin no era el de la prevención o tratamiento de la enfermedad de un individuo en particular, sino de aquellos actos que alteran la salud, el bienestar, el buen orden de la sociedad.

"Nadie - afirma el cirujano austríaco-, puede negar las utilidades y beneficios que resultan de la Medicina Forense y su estudio para la conservación del Estado, tanto en tiempo de paz como en el de guerra; como también que no hay foro alguno en la Legislación que (...) no necesite el auxilio y dictamen de la facultad Apolinea» (16).

La penetración y presencia entre los profesionales de la Medicina y la Cirugía españolas de finales del siglo XVIII de esta idea de que la Medicina ha de ser fuente de saber fundamental para los encargados de velar por el buen orden del Estado, se pone de manifiesto al contemplar el modo en que Juan Fernández del Valle se refería en las páginas de su Cirugia forense al papel que había de desempeñar la disciplina dentro de la dinámica social:

«Los objetos de la Cirugía forense se pueden reducir a dos, uno próximo y otro remoto: el primero se dirige a saber y conocer la verdad; el segundo es consiguiente y conspira a conservar la buena armonía y tranquilidad de un Estado» (17).

A la vista de lo anterior resulta evidente que, a finales del Setecientos y comienzos del Ochocientos, los profesionales de la Medicina eran absolutamente conscientes de la estrecha ligazón que existe entre ésta y la Política. Es más, como consecuencia de ello, los médicos van a reclamar para sí un lugar central en la administración del Estado. Sin 
renunciar a su papel como expertos testigos ante los tribunales, se sentían ahora, con lo que ello representaba para escalar posiciones dentro de la sociedad y aumentar su influjo y poder dentro de ella, como verdaderos maestros del Derecho.

Se explica así ahora mejor por qué en las primeras décadas del siglo XIX dos médicos españoles, los ya mencionados Ramón López Mateos y Francisco Fabra y Soldevila, se sintieron legitimados para escribir dos obras en las que, partiendo de los saberes que la Medicina les proporcionaba acerca de la naturaleza humana, pretendían proporcionar los principios fundamentales en que debían basarse los juristas a la hora de legislar, de establecer lo permitido y lo prohibido dentro de una determinada comunidad. Como era de esperar, entre esos principios se hallaban un buen número de ellos destinados a servir de guía en el establecimiento de las normas encargadas de regular tanto el papel de ambos sexos dentro de la sociedad, como su sexualidad.

Los puntos de vista de López Mateos acerca del sexo para el mantenimiento del buen orden social

Como he intentado mostrar en otro lugar (18), Pensamientos sobre la razón de las leyes derivada de las ciencias físicas, o sea, sobre la filosofía de la legislación, obra que Ramón López Mateos publicó en 1810 en Madrid, puede considerarse como la alternativa que un médico liberal español proponía para elaborar un nuevo marco jurídico que superara las estructuras del Antiguo Régimen. En su libro, en el que la influencia de Foderé y el pensamiento de los sensualistas franceses, de manera especial el de Pierre-Jean-Georges Cabanis (1757-1808), son evidentes, López Mateos proporciona, según hemos ya anunciado, los criterios extraídos de las enseñanzas de la Medicina acerca del hombre que en su opinión deben ser tomados como guía fundamental a la hora de llevar a cabo las tareas legislativas.

$\mathrm{Al}$ exponer las razones que le llevaron a escribir su libro, el autor señalaba lo siguiente:

"Advertía que toda ley justa se ha de fundar en razón o motivo, derivado mediata o inmediatamente de la naturaleza, y que el conocimiento de ésta era privativa de las ciencias físicas. Deseaba que los juristas, aprendiendo la ciencia del hombre moral por sus verdaderos principios, no se limitasen a meros consultores de las doctrinas 
y consejos de la medicina forense. El por qué de la ley se halla exclusivamente en las severas inducciones de la filosofía, o lo que es lo mismo, la legislación, para juzgar al hombre, ha de recibirle de manos de la física.

Estas y otras reflexiones (...) me parecían reclamar justamente el proyecto de una filosofía legal» (19).

De acuerdo con las tendencias de la época puestas de relieve en el párrafo anterior, López Mateos defiende la idea, recurriendo para ello a los postulados de ese derecho natural tan caro a los liberales, de que el papel de las «ciencias físicas» con respecto a la jurisprudencia no es meramente el de consejeras, sino que han de ser tomadas como la fuente única y fundamental de las leyes. Enseguida concreta el autor cuál es la «ciencia física» que debe ser tomada como punto de referencia fundamental de la legislación de un pueblo:

«La jurisprudencia se ha creído más de una vez autorizada exclusivamente para dirigir al hombre, sin acordar con ninguna otra ciencia sus resoluciones: y he aquí el origen común de infinitos desórdenes. Las leyes entienden en arreglar la moralidad de las acciones; y la medicina en averiguar los instrumentos que la determinan y modifican. Sin un exacto discernimiento de la variedad de circunstancias, que pueden concurrir a determinar y modificar esta moralidad, sugerido por la ciencia de la vida y de la muerte, mal podrá el legislador ajustar como debe sus preceptos a las insinuaciones de la naturaleza, y nunca pesará bien el mérito de las acciones en la balanza de la justicia» (20).

La Medicina sería, por tanto, a los ojos de López Mateos, la maestra del Derecho. Como poseedora de los saberes acerca de la naturaleza humana, sería el punto obligado de referencia a la hora de establecer los códigos legislativos encargados de regular la vida de los miembros de un Estado.

A tenor de cuanto llevamos expuesto, no puede dejar de verse en los Pensamientos sobre la razón de las leyes de López Mateos un ejemplo del creciente papel que han venido desempeñando los médicos, sobre todo desde finales del siglo XVIII, dentro de los mecanismos de control social. Independientemente del hecho de que los juristas tomaran más o menos en cuenta los postulados expuestos en obras como la que nos ocupa a la hora de elaborar los códigos legislativos, lo cierto es que esos principios que la Medicina establecía como fundamentales 
para el buen orden de un Estado, aun sin verse muchas veces materializados en leyes escritas, han contribuido de no escasa manera a fijar los patrones tolerados o intolerados de conducta de una determinada sociedad. Como ha señalado Peter, a medida que los médicos han conseguido granjearse una imagen de sabios portadores de una ciencia cierta e infalible, han ido imponiendo cada vez con más fuerza en la sociedad las normas de vida sana que la Medicina enseña (21). De este modo, los principios que sostiene López Mateos sobre el sexo en su obra pueden ser interpretados como la aportación de un médico al establecimiento de un nuevo modelo de sexualidad que la burguesía que él representaba trataba de imponer. Veamos pues cuáles son las normas de comportamiento sexual que este médico liberal español defendía como ideales para mantener en buen orden el Estado.

Un primer aspecto que hay que considerar es el del lugar y el papel que el hombre y la mujer deben jugar dentro de la sociedad. Desde una perspectiva naturalista, López Mateos sostiene que «las ocupaciones y sentimientos del hombre y de la mujer se derivan espontáneamente de la mayor o menor aptitud de su conformación orgánica» (22). Aunque como ha mostrado Elvira Arquiola en un trabajo reciente el empleo de la diferente complexión corporal del hombre y de la mujer como argumento para afirmar los tradicionales roles sociales asignados al varón y a la mujer venía de lejos (23), no es menos cierto que, tal y como ha expuesto Laqueur, los años finales del siglo XVIII fueron testigos de un incremento, sobre todo por parte de los pens: dores liberales, del recurso a las diferencias anatomofisiológicas del hombre y la mujer como recurso para mantener el viejo orden jerárquico entre los roles masculino y femenino (24). Este último autor ha llamado la atención sobre el hecho de que líderes destacados de la Revolución francesa se opusieron tenazmente al incremento de participación de las mujeres en la vida pública argumentando que su naturaleza física, radicalmente distinta de la del hombre y poderosamente representada en los órganos de la reproducción, las hacía incapaces para participar en la vida pública y las capacitaba mejor para desempeñar tareas en la esfera privada (25). Cabanis, una de estas figuras prominentes de la Francia revolucionaria, y que como señalé más arriba influyó notablemente en la obra de López Mateos, mantenía en efecto, según ha mostrado Staum, estos puntos de vista (26).

No debe extrañar pues que para el autor español la distinta constitución física del hombre y de la mujer, que siguiendo las doctrinas de la época consideraba como el resultado de la acción de «las partes de 
la generación» (27), sea la piedra de toque fundamental sobre la que va a establecer las diferencias entre los papeles que corresponde desempeñar al hombre y a la mujer en el seno de la sociedad. Así, al considerar el caso del varón manifiesta lo siguiente:

«El hombre es de fibra más fuerte, de menos texido celular y ménos humores que la muger: sus miembros son proporcionalmente más enxutos, su alzada mayor, su musculatura mas demarcada, y mas encorvados sus huesos; porque la contractilidad espontánea de la fibra, y la vigorosa y continua agitación de sus funciones, exprime los líquidos de la carnosidad de los músculos, los señala y doma los huesos que le sirven de puntos de apoyo. El sistema glandular es ménos numeroso, mas estrecha la cavidad de la pelvis, mayor el espacio de hombro a hombro, mas pequeños los pechos, las venas mas capaces, el pulso mas ancho y lento, grave la voz, y la piel mas bellosa» (28).

Esta constitución es, como dije, la base que determina, según el punto de vista de López Mateos, el rol social masculino.

«La firmeza de sus fibras le inspiró desde luego - al varón-aquella inclinación decidida por esfuerzos violentos que se descubre aun en las travesuras pueriles: él observó sus fuerzas superiores en mover grandes masas, y resistir á impulsos enormes (...): vio su constancia en tolerar exercicios de postura recta o en pie, de saltar, correr, andar (...): él sé probó en trabajos duros: se arrojó con ímpetu al peligro; en fin, él se formó hombre antes de saber que lo era.

Su constitución física le hizo de un carácter entero y sostenido, de un genio profundo, de un espíritu dominante y ambicioso, que arrogándose al supremo poder sobre la tierra, convenció que aun la muger era sombra suya en la sociedad, y no alzaba más figura que la que él quería darle» (29).

Del mismo modo es la naturaleza la que determina el papel que la mujer está abocada a desempeñar en la sociedad:

«Lo muy débil y sensible de la muger la inutilizó para grandes fatigas, y para negocios de discusión séria y detenida; al paso que la proporcionó a impresiones las mas ligeras, y á que tomase interés en cosas despreciables o de poca importancia. La conformación particular de los huesos de las caderas y demás que conforman la pelvis facilitaba la postura sentada, como también lo mas abultado de sus músculos por su gran texido celular, y mayor diámetro de su base, hacién- 
dola declinar a ocupaciones sedentarias y tranquilas. Sintió su flaqueza, reconocio el poder en el varon, y fió el dominarle á otro imperio que el de la fuerza. De aquí su propensión á ocupaciones de mas paciencia que talento, su comprehension pronta, pero variable, su carácter blando, insinuante y susceptible de infinitas modificaciones, su genio perspicaz para conocer y manejar los resortes del corazón del hombre, su economía moral y política» (30).

Así, pues, López Mateos continúa el discurso que la Medicina venía sosteniendo desde hacía siglos acerca del lugar del hombre y la mujer en el marco social. Pero ahora, debido al carácter de su obra, estas ideas tienen un alcance mayor. Ellas están destinadas a servir como guía a la elaboración de las leyes. En caso de ser tenidos en consideración por parte de los legisladores, ello supondría que la mujer que intentara adoptar el papel masculino se hallaría fuera de la ley. Y lo peor es que López Mateos exige que sus puntos de vista se tengan en cuenta, lo contrario significaría ir contra la naturaleza, romper con los principios del derecho natural, y eso equivaldría al caos. Así lo expresa en su obra:

«Mudad en los sexôs las ocupaciones y los destinos: ciencias, artes, cargos, guerras, navegación, todo lo violento y muy dificil sea de la muger; y del hombre las menudencias de la casa, el cuidado prolixo de los niños, las impertinencias de los enfermos, todo lo superficial y mecanico. ¡Qué variacion tan monstruosa! ¡qué desorden tan funesto! Desengañémonos, que el hombre se crió para hombre, y la muger para muger; los exâgerados progresos de algunas de éstas en armas y letras solo han servido a desnaturalizarlas en concepto de los verdaderos sabios (...). En saliendo la muger de su esfera fastidia, y pierde para con el hombre todo su mérito. ¿A quién no se le resiste una valentona en el estrado, ó una culta latiniparla?»(31).

López Mateos hace también extensiva su distinción de los papeles del hombre y de la mujer basada en la constitución, al terreno de las relaciones sexuales. En su opinión es al varón a quien debe reservarse la iniciativa tanto en su comienzo, como en su desarrollo, expresándolo en los siguientes términos.

«Contemplando lo material del acto venéreo aun en los brutos, se prueban mas las importantes miras de la naturaleza en haber criado á la hembra debil, y vigoroso al varón. El debía ser el agresor, ella la acometida: aquel debia triunfar, ésta rendirse á poca resistencia» (32). 
A través de lo anterior es posible constatar cómo López Mateos proporciona en su obra el estereotipo del rol femenino que la burguesía decimonónica defenderá: una mujer hogareña y sumisa al varón. Un papel que la obra del médico español eleva a la categoría de ley natural.

Un aspecto más relacionado con la sexualidad que está presente en la obra de López Mateos es el relacionado con las actitudes que el legislador ha de adoptar a la hora de establecer las normas destinadas a regular las relaciones sexuales. El autor considera al matrimonio como «el estado más natural del hombre civilizado» (33). Sin duda influido por la idea tan difundida en la época de que la riqueza de un Estado depende de la tasa de su población, solicita de los legisladores que eliminen todas las trabas que no teniendo justificación natural dificulten la celebración de matrimonios (34). Entre ellas se contarían también las limitaciones que puedan impedir el mantenimiento de relaciones sexuales completas en la vida conyugal:

«Los austeros rigoristas, queriendo hacer de las satisfacciones amorosas asunto de disparatada metafísica, han tratado de poner tasa en el uso del matrimonio á las sensaciones agradables: y de aquí otra prohibición, que aunque disimulada, amortigua los sentimientos mas enérgicos de la naturaleza, y la inhabilita para sus fines por una insulsa frialdad» (35).

López Mateos defiende, pues, un modelo de sexualidad que resulta útil para la economía del Estado liberal en cuanto tendía a asegurar la fuerza de trabajo. Pero los principios legislativos que sobre la vida sexual mantiene el autor español no sólo servirían para éso. Foucalt ha sostenido que desde mediados del siglo XVIII la burguesía estuvo empeñada en construirse una sexualidad que le sirviera para señalar y mantener su distinción de casta (36). No deben, por tanto, extrañar todos estos preceptos biológicos y médicos que un liberal como López Mateos propone para el buen orden del Estado. Ellos serían expresión en buena medida del proceso de acceso a la hegemonía social de la burguesía. A diferencia de la aristocracia nobiliaria, la burguesía habría cambiado la sangre azul de los nobles por la posesión de un organismo dotado de buena salud y por una sexualidad sana que asegurara la descendencia. No en balde López Mateos se ocupa de los peligros «del mal venéreo" y postula lo siguiente: 
«No contribuirá poco á extinguir el virus venéreo el que su existencia, comprobada en suficiente forma, se declarase por causa legítima impidiente y dirimente de matrimonio: zelando el Gobierno con toda vigilancia el cumplimiento de esta ley, y castigando severamente á los padres, tutores y á los mismos contrayentes, si verificaban el enlace contraviniendo á ella. ¿Por qué se ha de manchar el tálamo nupcial con un borrón tan abominable? ¿Por qué se han de arruinar y hacer desgraciadas las generaciones en el acto solemne y decidido, en que se trata de su felicidad y conservación? Cuidamos en el casamiento de nuestros hijos de ciertas etiquetas frívolas que nada influyen en su bien ni en el de la sociedad, y abandonamos á la suerte su salud y su vida como si fuesen de ménos importancia. Nos informamos de los intereses, preguntamos por el destino; y pasamos por alto la conducta, lo contrahecho y enfermizo del cuerpo y lo despreciable de la figura. Así nosotros que somos malos ya procreamos hijos peores, que darán con el tiempo nietos más desmedrados é infelices» (37).

El interés por la salud de los jóvenes tiene también expresión en la preocupación por los peligros de la masturbación. Al referirse a las enfermedades que pueden afectar a los jóvenes que conviven en centros cerrados alude a ellos del siguiente modo:

\footnotetext{
«Es necesario no perder de vista, que los jóvenes y muchachos que viven juntos en estas casas se comunican indispensablemente sus inclinaciones, sus resabios, y sus buenas o malas mañas. En sus entretenimientos y satisfacciones suele tomar parte cierta travesura maliciosa y sagaz, que adelantando intempestivamente los deberes de la naturaleza, y abusando de ellos con exceso, acarrea las hécteas nerviosas, la extenuación, el apetito voraz y otras enfermedades, o corta el paso quando menos al desarrollo, incremento y perfección de los miembros (38).
}

López Mateos pone así en juego esa guerra contra el onanismo que Foucault ha señalado como uno de los conjuntos estratégicos - los otros serían la "histerización del cuerpo de la mujer», la "socialización de las conductas procreadoras" y la "psiquiatrización del placer sexual»que se habrían desplegado a propósito del sexo como dispositivos específicos de saber y poder para producir esa sexualidad de la sociedad burguesa (39). 


\section{Los puntos de vista de Francisco Fabra acerca de la sexualidad}

La obra de López Mateos fue el antecedente inmediato de la Filosofía de la legislación natural fundada en la antropología o en el conocimiento de la naturaleza del hombre y de sus relaciones con los demás seres, una obra que Francisco Fabra y Soldevilla publicó en 1838 (40). Formado en Francia, Fabra trabó conocimiento, como ha mostrado Granjel, con la obra de Cabanis y otros sensualistas de la Francia postrevolucionaria y la influencia de éstos, así como la de Rousseau, se deja sentir en su Filosofía de la Legislación (41). Al igual que López Mateos, Fabra pensaba que el legislador debe actuar tomando los saberes que ilustran acerca del hombre como punto de referencia fundamental.

«Para penetrar con paso firme en el magestuoso templo de la legislación natural es indispensable consultar la ciencia antropológica para instruirnos de lo que es el hombre en cuanto hombre, cuáles son sus facultades morales y físicas, y cómo se halla constituido intelectual y corporalmente, del mismo modo que nos acojeríamos á la ciencia geológica o geográfica, si quisiéramos instruirnos de las formas interiores y esteriores de la tierra» (42).

De acuerdo con esto, Fabra justifica la diferencia de roles sociales entre el hombre y la mujer señalando que la desigualdad de fuerzas físicas e intelectuales entre ambos sexos procedería «de la naturaleza» (43). Sería, por tanto, un error del legislador establecer leyes contrarias a las que establece el derecho natural, justificándose así de nuevo el papel tradicionalmente asignado a la mujer.

Tampoco se aparta Fabra del modelo de sexualidad propio del pensamiento liberal cuando se ocupa de las relaciones sexuales y reclama mesura en la mismas aun cuando se lleven a cabo para satisfacer el instinto de reproducción. Para explicar la aparente contradicción entre el hecho de que la naturaleza no haya establecido «que el sentimiento que atrae a un sexo hacia el otro fuese un sentimiento de reflexión» sino la consecuencia de "un movimiento espontáneo» y la necesidad de controlar ese instinto primordial, Fabra recurre al ejemplo del «buen salvaje» y le pone como modelo de actuación. Un "ardor moderado" bastaría a éste, «a quien la naturaleza tiene irrevocablemente bajo su imperio", para asegurar la perpetuidad de la especie (44). Como era de esperar sostiene también, sin aludir sospechosamente ahora al modelo del hombre salvaje, que el modo más adecuado de satisfacer el «ins- 
tinto de reproducción» es «la unión perpétua o conyugal de dos personas virtuosas de sexo diferente» (45).

\section{Unas palabras finales}

A través de las páginas anteriores he intentado mostrar la visión que acerca de la sexualidad y su relación con el buen orden de la sociedad mantenían dos médicos españoles de las primeras décadas del siglo XIX. Las obras de ambos no sólo son exponente del nuevo lugar que los médicos estaban reclamando en su relación con el Derecho, sino que al defender los postulados fundamentales que al respecto estaba sosteniendo la cada vez más poderosa burguesía, contribuyeron a difundir en la sociedad el modelo de sexualidad que ésta pretendía imponer.

\section{NOTAS}

(1) Maravall, J. A. (1986): Estado moderno y mentalidad social. Siglos XV a XVII (2 vols.), 2, pp. 261-268.

(2) Un más amplio abordaje del problema de la salud como objetivo político en la España ilustrada puede verse en Martinez Pérez, J. (1989): La Medicina Legal en la enseñanza médico-quirúrgica de la España de la Ilustración, Madrid, pp. 47-57.

(3) Una panorámica de las diferentes normas sanitarias promulgadas por los gobiernos ilustrados ha sido proporcionada por GRANJEL, L. S. (1979): La Medicina española del siglo XVIII, Salamanca, pp. 117-130.

(4) Ṁanon, P. A. O. (1911): Médecine légale et Police Médicale (2 vols.), 1, París, p. 1. Se trata de la segunda edición de la obra. La primera apareció en 1802.

(5) Una más amplia exposición sobre el modo de entender la Medicina Legal por parte de estos autores y, de un modo más general, del contraste entre su modo de entender la disciplina y el que surgió a finales del siglo XVIII y comienzos del XIX puede examinarse en Martínez Pérez (1989), pp. 168-182.

(6) Según PAGEL, J. (1934): "Zacchias». En: Biographisches Lexikon der hevorragenden Ärzte aller Zeiten und Völker (5 vols.), 5, 1020-1021, Berlin-Wien, p. 1.021, el título completo del libro de Zacchia sería Questiones medico-legales in quibus ea materia medica, que ad legales facultetes vindetur pertinere, proponuntur, pertractantur, resolvuntur. Para Tourdes, G. (1874): «Médecine légale», en Dictionnaire Enciclipedique des Sciences Médicales ( $2 .^{a}$ serie), 5, 677-714, París, p. 711, ese título sería el de la edición aparecida en Amsterdam en 1651.

(7) También se aprecia este fenómeno, como lo testimonian las obras de Johann Daniel Metzger (1739-1805) y Joseph Jakob Plenk (1733-1807), en los países centroeuropeos. El primero de ellos afirmaba en su influyente Kurzgefasstes System der gerichtlichen Arzneiwissenschaft, Königsberg-Leipzig, pp. 1-2, lo siguiente: «La síntesis de todas las reglas o leyes procedentes hasta ahora de la Medicina para la administración de los Es- 
tados y la aplicación de las leyes, conforma la Staatsarzneikunde; una denominación nueva que, basada en los fines, reúne la ciencia de la Policía Médica y de la Medicina Legal. Aquella contiene las leyes médicas para la administración del Estado, y ésta las bases para la aplicación de las leyes». Los médicos se situaban así en dos momentos fundamentales del Derecho y de la administración del Estado: la elaboración y la ejecución de las leyes. Este mismo criterio es el que defendió el cirujano vienés J. J. Plenk en su Elementa medicinae et chirurgiae forensis, que sirvió de libro texto en numerosas facultades del Imperio Austro-Húngaro y de Rusia. A ella aludiré posteriormente al ocuparme de su influjo en la introducción en España del nuevo modo de entender el papel de la Medicina con respecto a las actividades jurídicas.

(8) Sobre el papel desempeñado por la medicina en la consolidación de la Revolución francesa véase LÉONARD, J. (1981): La Médicine entre les pouvoirs et les savoirs, París, pp. 11-66.

(9) FodERÉ, F. E. (1801-1803): Las leyes ilustradas por las Ciencias Físicas, o Tratado de Medicina Legal y de Higiene pública (8 vols.), 1, Madrid, pp. 1-2.

(10) Según Tourdes (1874): p. 700, y CoRBelLA, J. (1975): «Medicina Legal». En: Lain, P. (dir), Historia Universal de la Medicina (7 vols.), VII, 407-414, p. 411, el Cours de Médecine légale de Belloc habría sido editado por primera vez en 1800 Una segunda edición de la misma apareció en 1811, que sirvió de referencia para la versión en castellano de la obra que apareció en Madrid en 1819. Cito a través de la segunda edición de esta última. Belloc, J. (1827): Curso de Medicina Legal teórica y práctica (2 vols.), Madrid, p. 1.

(11) Belloc, J. (1927): p. 2.

(12) Varios autores han llamado la atención sobre el hecho de la escasa separación en cuanto a los límites de conocimiento existente con anterioridad al siglo XIX, e incluso dentro de esa centuria, entre lo que hoy entendemos por Higiene Pública y por Medicina Legal: Entre ellos destacan: ACKERKNECHT, E. H. (1977): «Legal Medicine in Transition (16th-18th Centuries)». En: Burns, Ch. (ed.) (1977): Legacies in Law an Medicine, New York, 252-260, p. 254; Sigerist, H. (1981): Hitos en la historia de la Salud Pública, México, p. 76; FISCHER-HOMBERGER, E. (1983), Medizin vor Gericht. Gerichtsmedizin von der Renaissance bis zur Aüfklarung, Bern-Stuttgart-Wien, p. 94. La beneficiosa influencia que para el desarrollo de la Medicina Legal en la Ilustración tuvo esa ausencia de límites précisos con la Higiene Pública ha sido puesta de relieve por mí en Martinéz Pérez (1989), pp. 46-83.

(13) Ese nuevo papel de maestros del Derecho que, a través del nuevo modo de entender la Medicina Legal, se atribuyen los médicos a finales del siglo xviII y comienzos del XIX fue ya apuntado por PeSET, J. L. y. PeSET; M. (1975): Lombroso y la Escuela Positiva Italiana, Madrid, pp. 88-89.

(14) Sobre el lugar preponderante de la obra de Plenk en los primeros años de la docencia de la Medicina Legal en San Carlos puede verse Martinez Pérez, J. (1988): «Sobre los inicios de la enseñanza de la Medicina Legal en España: las lecciones de Ribes en San Carlos». En: Valera, M.; Egea, M. a A.; Blázouez, M. ${ }^{a}$ D. (eds.): Actas del VIII Congreso Nacional de Historia de la Medicina (3 vols.), 1, Murcia, 171-190.

(15) PlenK, J. J. (1796): Medicina y Cirugia forense o legal, Madrid, p. 1.

(16) Plenk (1796): s. p.

(17) FERNÁNDEZ DEL VALLE, J. (1796): Cirugia forense general y particular, dividida en quatro partes, que son: Cirugia forense Civil-Política, Militar, Canónica y Criminal (3 vols.), 1 , p. 62 .

(18) MARTINEz PÉrez, J. (1988): «Medicina, liberalismo y legislación: Ramón López Mateos (1771-1814) y sus Pensamientos sobre la razón de las leyes", Asclepio, 40-2, pp. 209-246. 
(19) Lopez Mateos, R. (1810): Pensamientos sobre la razón de las leyes derivada de las ciencias físicas, o sea, sobre la fjlosofía de la legislación, Madrid, p. IV.

(20) LOPEZ MATEOS, R. (1810): p. 3

(21) Peter, J. P. (1980): «Les médicins et les femmes». En: Aron, J. P. (ed.) (1980): Miserable et glorieuse. La femme du XIXe siécle, 79-97, París, pp. 79-87.

(22) LOPEZ MATEOS (1810): p. 15.

(23) Arquiola, E. (1988): «Bases biológicas de la femineidad en la España moderna (siglos XVII y XVIII)", Asclepio, 40-1, pp. 297-315.

(24) Laqueur, T. (1987): "Orgasm, Generation, and the Politics of Reproductive Biology». En: Gallagher, C.; y Laqueur, T. (eds.) (1987): The Making of the Modern Body. Sexuality and Society in the Nineteenth Century, 1-41, Berkeley-Los Angeles-London.

(25) Laqueur (1987): p. 18.

(26) Staum, M. S. (1980): Cabanis, Princeton, pp. 213-217.

(27) Lopez Mateos (1810): p. 13.

(28) LOPEZ MATEOS (1810): p. 15.

(29) LOPEZ MATEOS (1810): pp. 13-14.

(30) LOPEZ MATEOS (1810): pp. 14-15.

(31) LOPEZ MATEOS (1810): pp. 20-21.

(32) LOPEZ MATEOS (1810): pp. 19-20.

(33) LOPEZ MATEOS (1810): p. 110.

(34) LOPEZ MATEOS (1810): pp. 115-116.

(35) LOPEZ MATEOS (1810): p. 114.

(36) Foucault, M. (1984): Historia de la sexualidad, 1. La voluntad de saber, México, pp. $149-154$.

(37) LOPEZ MATEOS (1810): p. 271.

(38) LOPEZ MATEOS (1810): p. 241.

(39) Foucault, M. (1984): p. 126-129.

(40) Sobre la figura y la obra de Fabra pueden examinarse: GranJEL, L. S. (1967): «Nota sobre la "Filosofía de la Legislación natural" del Doctor Fabra y Soldevilan. En: GRANJEL, L. S. (1967): Médicos españoles, 264-278, Salamanca; Comenge, L. (1914), La Medicina en el siglo XIX. Apuntes para la cultura médica en España, Madrid, pp. 566-568; y GoNzÁlez CRespo, M. J. (1840): Elogio histórico del Doctor D. Francisco Fabra Soldevila, Madrid.

(41) Granjel (1967): pp. 269 y 272.

(42) FABRA, F. (1838): Filosofía de la legislación natural fundada en la antropología o en el conocimiento del hombre y sus relaciones con los demás seres, Madrid, pp. II-III.

(43) FABRA (1838): p. 179.

(44) FABRA (1838): p. 32.

(45) FABRA (1838): p. 303. 